"For one week after the operation the pulse of our patient was uniformly 100-hard and wiry; after that time it came down at the rate of two per day, till it fell to seventy.

"I kept lier on water, then gruels, then broth, and finally on bread and meat till well. T'o give rest and comfort, I dosed her freely with morphine; and, as a peculiarity (and what I believe to be an improvement), I gave no laxative, but left the bowels to take care of themselves, which they did perfectly; and passed the first facal matter, quictly, easily, and uaturally, at the end of twenty-five days, when all was well.

"I kept her in bed five weeks; but I think she might have risen sooner. In seven weeks she walked the streets, and attended church; from that time she has done her own work (I mean that of her own family), with all the comfort of former years. She tells me she never in her life felt stronger or firmer than now, and in all respects her health is as perfect as possible."

\title{
MENSTRUATION AND ITS CONNECTION WITH UTERO-GESTATION.
}

By Amos Nourse, M.D., Bath, Maine.

[Communicated for the Boston Medical and Surgical Journal.]

UNTIL recently the subject of menstruation, though much discussed, has been but little understood. The discovery that it oceurs simultaneously, or nearly so, with the disengagement from the ovary of a mature ovum, advances us at least one step in knowledge, and may lead, if properly followed up, to a pretty definite comprehension both of its relations and object. Indeed, in the opinion of some physiologists, it has already done so-they regarding it as fully proved that ovulation and menstruation are absolutely identicalpart and parcel of the same process-the discharge of a mature ovum being the actual function, while the bloody discharge from the uterus is but the outward sign or manifestation. And the analogy of nature is invoked to prove that the season of menstruation in the human female corresponds entirely to that of heat in other animals.

To this doctrine, thus broadly stated, I have never been able to yield my assent. It seems to me to contradict established facts. If it were true, the sexual passion of the human female should be strongest while the menstrual flow is upon her; and who does not know the fact to be directly otherwise?

Then, too, in all our domestic animals, copulation, in order to be effective, must be had during the heat; and so, if the analogy insisted on is to be trusted, there is not an individual existing in this wide world, who was not begrotten in that season of uncleanness, when women instinctively shrink fiom contact !

No wonder that the argument from analogy leads us here to such absurd conclusions, for it has no solid substratum to rest upon. If 
it were apparent, or could be proved, that the phenomena connected with generation in man and other animals werc entirely analogous so far as known, that to be sure would afford a presumption more or less strong in favor of identity in those concealed from view. But there is no such general agreement-far fiom it. In the animals we are acquainted with, not only is the season of heat the only time when the overtures of the male mect a gracious reception, but, at all other times, any advances on his part are sure to be very significantly, if not spitefully, repelled. And, if intercourse, under such circumstances, is forced upon the female, it is never found to be offective.

Again, indications of sexual passion are never witnessed in animals during the pregnant condition. How cntirely different in the human species, I need not say. Now, in view of such diversities, and even contraricties, who does not see that any attempt to reason from analogy, so far from enlightening, can only tend to mislead?

In considering and discussing the subject of menstruation, we are apt, consciously or unconsciously, to take it for granted that it has something to do in effecting fecundation. But to my mind, such an assumption is wholly gratuitous. That menstruation gives indication of a capacity for impregnation, we have abundant proof, both negative and positive. But that it exerts eren the smallest agency in accomplishing the fecundating act, has never yet been proved, nor, as I think, rendered eren probable.

The all-important functions of the uterus are, so far as known, to give lodgment to the embryo-to furnish pabulum for its growth and development-and, at a proper time, to expel it. These all, it will be perceived, have relation, not to conception, but to utero-gestation. Is or is not the function of menstruation subsidiary to the same process? We shall see.

If wo glance for a moment at the successive steps in the process of reproduction, two things can hardly fail to attract our notice. One is the remarkable, and almost intelligent sympathy felt and expressed by and between the organs concerned; and the other, the wonderful changes, both in dimensions and structure, which the uterus is made to undergo, preparatory to, and in the performance of, the special functions which the pregnant condition devolves upon it. And these two phenomena, if properly considered, furnish, in my judgment, a key to the mystery we are endeavoring to solve.

Dr. Dalton informs us that no sooner is the generative process commenced, than the lining membrane of the uterus assumes a changed, and altogether pcculiar structure, fitting it for imparting to the embryo the nourishment it requires. And Dr. Janser, on carefully inspecting the uterus of a girl murdered four days after menstruation, found the structure and appearance of its mucous surface to be precisely such as, according to Dr. Dalton, belongs to incipient pregnancy. To quote his own words, "it results," he says, "from this 
observation that the mucous membrane of the uterus presents, during menstruation, characters analogous to those which exist during gestation."

Now how comes it about that this remarkable change of structure, wrought out ouce a month in and by the process of menstruation, should constantly occur in the non-pregnant state, as well as when conception has taken place?

If we consider well the circumstances under which it occurs, and keep in mind, too, how continually the action of one organ in the sexual system is influenced, and even controlled, by the state and condition of another, the change in question will cease to be the subject of marvel, and the wonder will be rather that the why and the wherefore have so long been overlooked.

Why is it that, so soon as the uterus has taken into its custody and maintenance a vivitied germ, the mamma proceeds at once to take upon itself a new and peculiar action preparatory to the new function it instinctively feels it is about to be called upon to per. form, 'viz., that of lactation?

How is it, too, that, when the process of utero-gestation is approaching its natural termination, the structure of the cervix uteri, of the vagina, of the external labia, and even of the perinæum, becomes so changed as to enable them to bear with impunity the impending strain that would otherwise prove futal to their integrity? In both cases the organs concerned almost seem to be endowed, not only with intelligence, but with forethought. Certain things, they perceive, are taking place in their associate organs, the result of which is to be that a new and laborious duty will shortly be thrust upon them, and they proceed to prepare for it.

In like manner, when the ovarium is maturing a germ, the nucleus of an embryo that is to be, the uterus takes note of the fact, and recognizes in it the commencement of a process in which she is to play a most important part. True it is, as we happen to know, that all this labor on the part of the ovary may go for nothing, and the product become effete; but this the uterus does not know-how should it? It can take cognizance only of what transpires in the system to which it belongs, and of which it forms a part. And, so far as the work of that system is concerned, the embryo is already perfected, when the germ is fully matured. As soon, therefore, as this process is nearly completed, the uterus feels herself called upon to prepare for the reception and nutrition of the product. Whether or not the anticipated event is destined to be realized, time and chance must determine. But she has no knowledge of or control over that contingency. The ovary, she knows, is engaged, seriously and in earnest, in the great function of reproduction, the special office for which nature formed and fashioned it; and she doubts not, has no occasion to doubt, of its success in the performance of it. It is her business, therefore, in every case in which a mature and 
perfect ovum is being elaborated, to prepare for its reception, in utter disregard of the question of fecundation, which she could not settle if she would. She does thus prepare herself; and the process in and through which the requisite change of structure is effected, we call menstruation. It has nothing to do, if I judge rightly, either in promoting or preventing the fecundating act, but is simply a preparation of the uterus for a fitting discharge of the new duties which prospective utero-gestation is about to impose.

This vicw of the subject gives to menstruation an intelligible object and office. How it is that the bloody discharge becomes instrumental in effecting the contemplated change of structure, or why it should be regularly and constantly incidental to the process, I pretend not to understand, and shall not attempt to explain. It is the result alone of menstruation that $I$ have to deal with. And that result, according to Dr. Janser, is a change of organization in the mucous lining of the uterus, precisely similar to that which belongs to the early stage of utero-gestation.

Now, should this asserted identity prove, after all, to be purely imaginary, I shall perhaps have little to say in defence of the views I have here submitted. But, should future observations confirm the truth of Janser's statement, and the appearances described by him be found uniformly to attend the menstrual process, then I see not how the conclusion I have arrived at can well be avoided.

Bath, June 22d, 1864.

\section{SARATOGA SPRINGS.}

[Oommunicated for the Boston Medical and Surgical Journal.]

Messrs. Edirors,-Now is the time for physicians to send their "chronic cases" to Saratoga. Never has the village been in a better condition to receive them, than at present. Extensive improvements have been made in nearly all the large hotels, and private boarding-houses have been onlarged and improved, so that our capacity for accommodating boarders has been increased nearly one quarter since last season.

Invalids have been coming in since May. Dyspepsia, hypochondria, and most of the nervous discases, are well represented. Not a symptom is wanting. Great numbers of scrofulous patients visit us, especially from the New Ingland States; together with patients affected with the different kinds of skin discases, rheumatism, urinary diseases, and "miserable chronic cases," from all parts of the country. Now, Gentlemen Editors, strange as it may appear, most of these invalids are improved by a judicious use of our mincral water, and many entively recover.

No doubt our fine air and healthful climate contribute essentially to these results, as well as relief from home cares and business.

VoL. Lxx.-No. 25* 